\title{
Multiplicity of Voices in Community Development through Radio in Fanteakwa District, Ghana
}

\author{
Manfred K. Asuman \\ Geopat Consultancy Ghana \\ Africanus L. Diedong \\ (Corresponding Author) \\ Department of African and General Studies, University \\ for Development Studies, Wa Campus, Ghana \\ langyin45@gmail.com \\ DOI//http://dx.doi.org/10.4314/gjds.v16i2.9
}

\begin{abstract}
The study examines community radio as a channel for development through people's participation in development activities in the Fanteakwa District of Ghana. The study argues that participation of people is necessary for development. The study employed the concept of participatory development communication and the empowerment theory to help understand the role of community radio in development. Mixed method research design was used for the study. Data was collected through survey questionnaires and semi-structured interviews. Purposive sampling and multi-stage sampling techniques were used to select respondents. It was found that participation is highest amongst people whose preferred channel of contribution to development initiatives is Radio Listenership Clubs. Though community radio station is serving the community, more needs to be done to properly integrate it into the lives of the people. Another finding was that community radio is not necessarily owned by the community, but can be the result of an individual's entrepreneurial effort. It is concluded that the integration of participatory approaches in radio programming and ownership is relevant because they are more people-centred and can be sustainable. A legislation on community broadcasting is recommended in order to define the role of individual entrepreneurs and NGO's in establishing community radio stations.
\end{abstract}

Keywords: Community Radio, Community Development, Participation, Empowerment, Fanteakwa District 


\section{INTRODUCTION}

In Africa, community radio is a part of the democratisation process that spread across the continent in the early 1990's. In parts of Sub-Saharan Africa, including Ghana, the democratisation process resulted in deregulation and liberalization of broadcasting from authoritarianism to a much more participatory, democratised and liberalised broadcasting system (Lingela, 2008: 124). Community Radio has enabled people find their voices and self-worth. However, Diedong and Naaikuur (2012) argue that one of the weakest points in communication for both state-owned and commercial radio stations is their undying desire for setting the agenda for the discussion of development issues on their own terms. According to them the most amazing thing about community radio is its potential to allow local people to determine the development dialogue. This means that popular participation in the management and production of programmes is key in running community radio. Fraiser and Estrada (2001), argue that for the successful running of community radio, there must be community ownership and democratic management in the production and programming process. Participation in programming can be assured with inclusive production formats that encourage and support programme production by organizations from within the community. This can be augmented by facilitating broadcasting public forums, and generally by enabling the free and open exchange of views through horizontal communications between individuals and groups (Teer-Tomaselli and De Villiers, 1998). Participation in community radio also allows long-neglected people to be heard and be included in the democratic process.

In Ghana, despite high interest in the establishment of community radio little attention is focused on the need for community radio stations to become avenues for people to be actively involved in livelihood and local governance issues. The problem of the study is that in the Fanteakwa District though there is a community radio station, it is unclear how citizens participate in programme production and to what extent the radio station gets people closer to their elected representatives in the district assembly, what methods of participation they deem effective and how they contribute to the management of the community radio station, even though the Fanteakwa District Assembly has made efforts to include local people in policies and regulations formulation.

Low participation of people in development projects and other related governance issues is attributable to their weak voice in such issues. The importance of community radio in improving local governance is highlighted when Lennie and Tacchie (2013: 5) assert: "Community radio provides an avenue for local governments to improve practices, learn from citizens and help achieve sustainable development through engagement of people on the ground." The potential of community radio 
in aiding local people to take ownership of their development cannot be realised unless attention is paid to the principle of participation and how it can be improved to make citizens the central point of the community development process. The focus on participation is vital because people's engagement in developmental issues at the local level often serves as a starting point for development planning and implementation of policies.

\section{LITERATURE REVIEW}

\section{Community Participation in Development Initiatives}

The desire of community members to be part of the affairs that affect their lives is what moulds the dynamic process of participation. Community participation in development initiatives is an evolutionary process whereby beneficiaries influence the direction and execution of development initiatives as participants playing active roles and not just mere recipients of projects benefits (Bamberger, 1990). This means some form of involvement of people with similar needs and goals in decisions affecting their lives. Community participation is a cyclical process which is also cumulative in nature, therefore becoming the locus of community empowerment

Community participation in development initiatives are promoted on the basis that they support effective project implementation and enhance the welfare of the poor. Okinda (2001) gives a typical example of community participation in developmental initiatives using an example of the construction of a dam and the improved agricultural production in the Lake Region of Kenya as a result. Although the poor are becoming increasingly involved in the various stages of development initiatives, questions are raised if their inclusion constitutes veritable participation and whether people have been empowered in ways to enable them control their destinies and determine the direction of their development. Not all participation is the same. Some academics assert that community participation in development initiatives involves seeking public inputs at specific points in the decision-making process on the specific issues where such input has a real potential to help shape the decision or action to be taken (Samah and Aref, 2009). This study seeks to interrogate what specific points in the development process, community participation is needed.

Community participation in development initiatives may produce results that were never foreseen at the onset of a particular development project. The most instrumental forms of participation can provide the spark that can in some contexts lead to popular engagement around particular issues, which bring about changes in attitudes amongst local people. Barasa and Jelagat (2013) recall an instance in rural Namibia, where a team of experts using a simple participatory appraisal exercise to 
explore issues in child nutrition were stunned when the villagers were so incensed by what their discussions suggested that they decided to mobilise and demonstrate at the offices of their local assembly to demand accountability from them (Barasa and Jelagat, 2013). Indeed, many development initiatives have failed because the people who were to benefit from the intended project were not listened to (Karikari, 1999).

\section{Participation in Community Radio}

Participation in community radio is valued for both intrinsic and instrumental reasons. The intrinsic value refers to the idea that the act of participation is valuable in itself, quite apart from any value it may have in helping to achieve other good things. Amartya Sen's forceful exposition of the idea of "Development as freedom" clearly recognises the intrinsic value of participation in the development process (Sen, 1981). In this perspective, development consists of the expansion of a range of freedoms to do and be the things that human beings have reason to value, and the freedom to participate meaningfully in communal matters is recognised as one of those valuable freedoms (Sen, 1981).

Boafo and George (2001) acknowledge that, participation is not limited to the context of development. It is a highly general right that has a bearing on all spheres of public affairs, and as such it is equally applicable in developed as well developing countries. Thus the universality of the right to participate has been recognised beyond dispute, underlining the intrinsic value of participation in all spheres of public life. Comparing its relationship with two other concepts, namely, empowerment and social capital can further explain the instrumental capacity of participation. These two may be considered as intermediate variables through which participation promotes efficiency and equity. Varshney (2002) suggests, the casual link between participation and empowerment is straightforward. In normal processes of governance, in which decisions are taken by politicians, bureaucrats and technocrats, ordinary people are powerless to influence the decisions that may have far reaching consequences for their lives and livelihoods. Even if those decisions happen to be favourable to them, the fact remains that they are at the mercy of a distant group of decision makers over whom they have very little control. Participation can change all that. The very presence of ordinary people at the discussion table will give them some power to influence the decision making processes and their outcomes, even if they are not able to participate on equal terms with the elite decision makers (Varshney, 2002). Therefore, Varshney (2002) argues that facilitating participation does not mean merely "making others participate", but rather engaging stakeholders in dialogue, or better a "multilogue". 


\section{Development and Community Development}

Development means different things to different people. Bekye (1998) notes that current development strategists no longer work with either the narrowly economic, or the esoteric humanistic view of development. The broad-based view of development is relevant because it considers the holistic development of people. Community development is a shared attempt at improving the quality of life of members of a particular community. Therefore, development cooperation of governments and NGOs has consequently greatly shifted focus in the development debate. More than ever they talk now of cooperation in development, partnership, do-it-with them, instead of the do-it-for-them orientation of previous years (Bekye, 1998:38).

In an integrated approach to community development it is important that members of the community to have a role to play in the planning and execution development projects. In the process of executing development activities, a key factor in facilitating the process is for the community members to cooperate with other stakeholders. Attempts by development agents to improve the livelihoods of people require the sharing of information among people in order to enable them appreciate what is going and be pre-disposed to support the process. Meaningful development happens in communities in a context whereby there is the facilitation of the active involvement of different community groups, together with other stakeholders involved, and the many development and research agents working with community and decision-makers (Bessette, 2004).

\section{Theory of Empowerment}

Questions about empowerment - what it is, how it develops, the conditions in which it occurs, and how empowerment at one level influences another; have preoccupied researchers in many areas of social research for many years. Empowerment cannot be discussed as an individual phenomenon, but it must also be investigated in connection with the social setting in which it appears. This implies studying not only individual change, but also changes in the social setting itself (Wallerstein, 1992). An empowered community is one in which individuals and institutions apply their skills and collective efforts to meet their required needs. In an African sense, empowerment manifests in a community whose understanding of life is anchored on the philosophical orientation that "I am because we are" (Ubuntu). Archbishop Desmond Tutu noted: "You might have much of the world's riches, and you might hold a portion of authority, but if you have no ubuntu, you do not amount to much". It is the spirit of Ubuntu that builds community. Community radio empowers people by giving them space to share their lives and project their humanity in diverse 
ways through effective programming. An empowered community has the ability to influence decisions and changes in the larger social system. For empowerment to be a meaningful concept, and different from others such as self-esteem and social efficacy, the cultural, historical, social, economic and political contexts in which the individual exists must be recognised (Rissel 1994).

Kieffer (1984) identifies two themes which underlie the movement through all phases of the development process: firstly, the function of a continuing internal constructive dialogue which is also known as the creative force of internal contradiction. Secondly, the existence of constructive channels which provide resources for resolving these continuing internal confrontations. She adds that the process of empowerment is enhanced by sense of community, and that psychological sense of belonging plus collective political or social action plus an actual increase in control over resources constitute community empowerment (Kieffer, 1984). Thus, an increase in control over community resources, or a positive change in the socio-political environment plus a reported increase in the sense of belonging are the appropriate end points for analysing empowerment.

Wallerstein (1992) proposes an empowerment model which has the following assumptions of success: the act of participating in the development of ones' community promotes changed perceptions of self-worth and a belief in the mutability of harmful situations, which replaces powerlessness. The experience of mobilizing people in community groups strengthens social networks between individuals and enhances the community's competence to collaborate and promote communal development.

The link between community radio and empowerment is a strong one. In community radio, local people are voluntarily participating and producing programmes for their own benefit. Community radio plays an important role in the lives of rural communities as it creates awareness, provides information and education and improves the process of accountability (Ugboajah, 1985). Therefore, it becomes a platform for shared voices on diverse issues of community interest.

Community radio empowers people by allowing them to acquire the ability and opportunity to participate and contribute in the development process creatively and meaningfully (Reiser and Gagne, 1982). Community radio in particular and the mass media in general are the chief agents of creation, preservation and eradication of different kinds of images and stereotypes against the vulnerable in society. The information local people receive through radio broadcast, shapes their opinions about the power and authority they wield within their immediate environment (Ansah, 1979). 
Community radio is a key component in participatory development because, it can help to overcome, "isolation" which is a key component of poverty. Local news and educational programmes can greatly enhance transparency, a cornerstone for of democracy. Evidently, better knowledge of development projects promotes higher levels of participation and ownership, and discourages corruption (Reiser and Gagne, 1982).

\section{Figure 1: Conceptual framework on community participation in development}

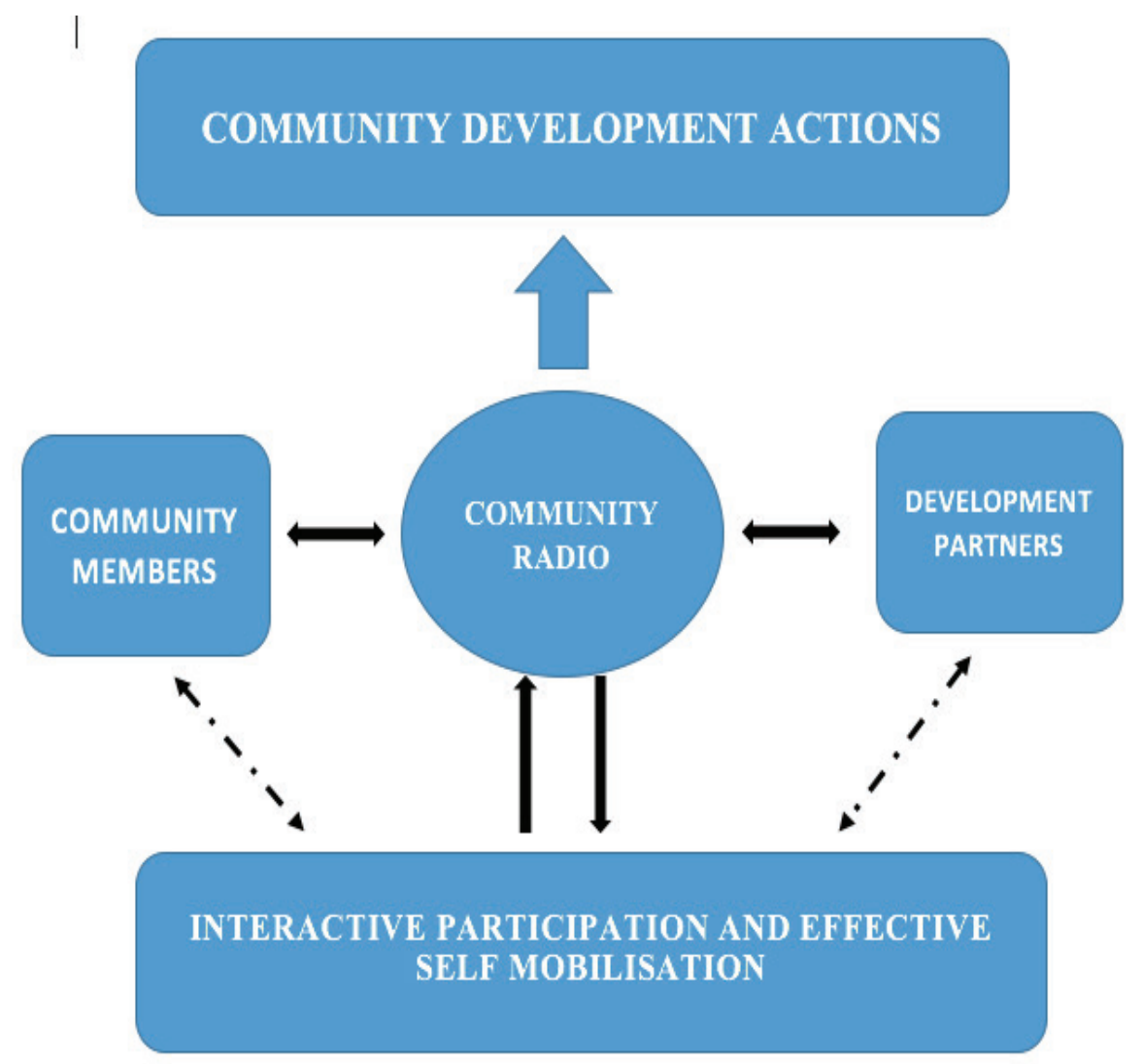

Authors' construct, December, 2017

The concept of Community Radio strongly espouses the theory of empowerment. The key feature of the Empowerment Theory is social inclusion and participation of local people in their development. Community Radio can be a driver of initiatives aimed at improving the quality of lives of community members. Community members sometimes on their own, undertake projects and programmes on development. At other times, external development agencies such as NGO's, donors and government support them in development, or collaborate with them. 
These development initiatives require a process of interaction and sharing of information, skills and knowledge. If people must be empowered to take charge of development initiatives, the platforms for interactions and their outcomes thereof need to be governed well. Therefore, in the engagements at different levels geared towards finding solutions to development issues, information on issues of transparency, inclusiveness, accountability, and responsiveness are vital. Community radio acts as a facilitator by ensuring the dissemination of information and news which is useful for engaging of all the partners in the development process. Essentially, how meaningful and beneficial the efforts of the community and their participation will be, as facilitated by Community radio can be based on two deeper levels of participation: interactive participation and participation through self-mobilization. Community participation, derives its strength from these two factors which are critical for participation to become a process of empowering people, so that they can take control over their own resources and lives.

Community Radio recognises the help needed from development partners but also infuses the role of local people in the discussions that surround and sets the agenda for their development. Community radio becomes a rallying point to solicit information from the various development agents (both internal and external) through dissemination of local ideas and local interest in the community development process.

\section{METHODOLOGY}

The study adopted the mixed method research approach. By mixing both quantitative and qualitative data, the researcher gains in-depth understanding and corroboration, while offsetting the weaknesses inherent to using each approach by itself (Lofland and Lofland, 1995). Quantitative data was collected using survey questionnaires. Qualitative data was collected using semi-structured interviews. Multi-stage random sampling and purposive sampling was used to select respondents. The sample size was three hundred and eighty-eight respondents. Five of the respondents were purposely selected to participate in semi-structured interviews. Purposive sampling was used to select two producers of Nopras 107.5 FM, the District Director of Agriculture, Chairman of the Novisi Vegetable Growers Association and the leader of the Konkomba fishermen group were interviewed. Three hundred and eighty-three of the respondents were selected randomly in a multi-stage sampling process to participate in the collection of quantitative data. 
In the first stage of the multi-stage sampling process, the lottery method was used to select six out of the ten urban/area/town councils of the district - Begoro, Bosuso, Abooho, Ehiamankyene, Osino and Feyiase.

In the second stage of the sampling process, systematic style was used. The fifth household in the electoral area is chosen and thereafter, the ninth in every sequence is chosen until each electoral area has exhausted its allocation. The number of respondents in an electoral area is allocated according to the population proportion of the electoral area in the district. A total of five interviews took place. The interviewees were the Programmes Manager of Nopras 107.5 FM and another programme producer at the station, the District Director of Agriculture (DOA), the Chairman of the Novisi Vegetable Growers Association and the leader of the Konkomba Fishermen Group.

\section{The Study Site}

The Fanteakwa District was carved out of the East Akim District in 1988. The district shares boundaries with Kwahu Afram Plains South district to the north, to the northwest by Kwahu South district, the south by East Akim and Atiwa district and to the east by Yilo and Upper Manya Krobo district. It is bonded to the north by the Afram Plains, and the Volta Lake to the North West. The district has a total land area of 1150 square kilometres being currently the third largest district in the region in terms of land size. The district is predominantly a forest zone with few semi-savannah areas at the Northern part. The typical wet - semi deciduous forest vegetation covers about 80 percent of the total vegetation cover across the district. This vegetation is therefore suitable for the cultivation of cash crops like cocoa, coffee, rubber, oil palm and citrus as well as stable food crops such as plantain, cocoyam, cassava, maize, rice and vegetables. Most of these crops are exported which help generate more income for farmers, the district and the country as a whole. The religious affiliation in the district follows the general pattern of that of the country with Christians (88.2\%) being the majority followed by Moslems (5\%) and Traditionalists (0.7\%). Also found in the district are persons with no religion (5.1\%) (GSS, 2014).

The predominant occupation in the district is agriculture and related trades (about $75 \%$ of the labor force are in crop farming or aqua culture), whilst the remaining (25\%) are petty traders/commerce, artisans (auto and radio mechanics, sewing, masonry, wood carving, beads making, smiting, sign-writing, painting, decoration and carpentry) and the service sector. The District is endowed with large tracks of arable land suitable for the cultivation of mangos, cocoa, cereals, roots, vegetables, plantain, banana, yam, etc. in commercial quantities. 
The district is selected for the study because of a combination of several factors. It has an active community radio station and also, possesses a mix of livelihood sources. This allows the researcher to suitably examine the central themes in the study to adequately answer research questions. Demographic characteristics of the district provides the basis of analysis and comparison in areas such as; how level of education affects participation in community initiatives. The relationship between employment type and participation in community radio will also be drawn. Besides participation, the study will also analyse the importance the community radio station places on local governance issues. This is key because, one of the guarding principles of community radio is to improve the effectives and accountability of local governments through self-representation and provision of information.

The Fanteakwa district as a political, planning and administrative authority performs among its responsibilities, deliberative, Legislative and executive functions.

\title{
FINDINGS AND DISCUSSION
}

\section{Programme Focus and Local Livelihoods}

The radio has implemented programmes in agriculture which is the major source of employment for people in the district. Making reference to a project called Mobilizing Action for Agricultural Sector Improvement (MAASI), programme producers noted:

\begin{abstract}
About $80 \%$ of the internally generated funds of the District Assembly is earned from farmers and market women and all their activities, which are sometimes directly or indirectly related to agriculture. But we realised the Assembly wasn't doing enough to improve the lives of farmers and market women in the district. That is why with the help of the United States Agency for International Development (USAID), under the Feed the Future Programme, the MAASI project was introduced. The project sought to gather all the stakeholders in agriculture and district finance and budgeting to build their capacity, using the radio station and the Assembly as the rallying point for the district to invest more and spend more on agriculture in order to benefit the people. This programme ran for thirteen months and ended in February this year (2017), and we can already see some results. (Field Interview, December 2017)
\end{abstract}

A radio documentary known as "Education Watch" discusses various topics in education as an example. The producers of the radio station believe that, through 
educational programming, Nopras FM can make people aware of their capabilities, thereby ameliorating their livelihoods.

One of the objectives of this study was to find out if the programming of community radio influences the livelihood of community members. Therefore, it was important to find out the kind of information Nopras FM provides to households. About $31.59 \%$ of the respondents identified news as the kind of information provided by Nopras FM. A total of $22.45 \%$ replied that programmes by Nopras FM provides them with agricultural information, 20.63\% of the respondents indicated that Nopras FM provides them with information on local development issues. On the other hand, $\mathbf{1 4 . 1 \%}$ respondents said the programmes of Nopras FM provides them with entertainment. Whilst $7.31 \%$ of respondents said Nopras FM provides them with market prices, $3.92 \%$ answered in the affirmative for health information.

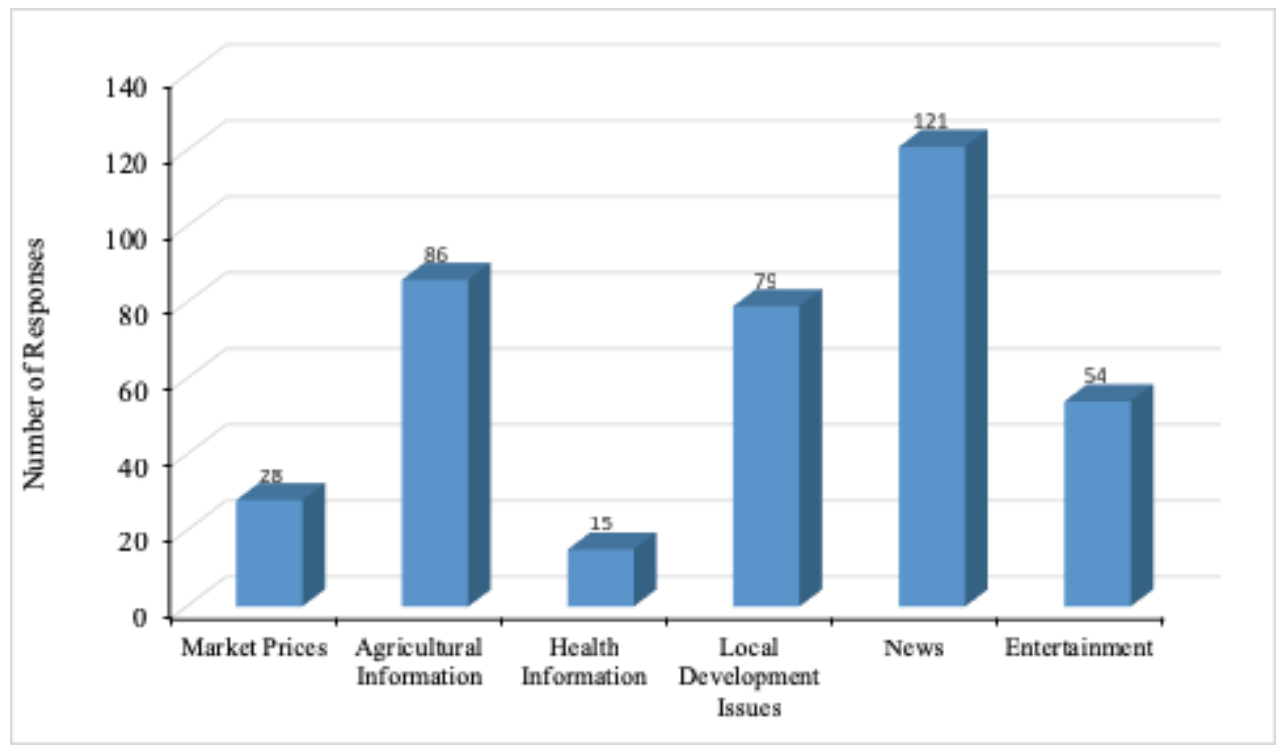

\section{Figure 2: Information provided by Nopras FM to households}

The researchers sought to find out if the information provided by the programming of Nopras FM has affected or shaped the standard of living of the households of respondents in any way. One hundred and five respondents (24.42\%) identified radio information from Nopras FM as having no impact on their household's standard of living. Eighty (20.89\%) respondents considered programming from Nopras FM as having a somewhat useful influence on their household standards of living. One hundred and eight $(28.2 \%)$ respondents said radio programmes are of moderate use in improving their household's standard of living. Fifty-four (14.1\%) respondents, however, indicated that radio programmes have a very useful impact on their 
household standard of living. Thirty-six respondents (12.39\%) were confident that information from Nopras FM has played a vital role in improving their household's standard of living.

Table 1 presents a bivariate chi square analysis between employment and the impact of Nopras FM on household standard of living. The test shows a strong relationship between employment and how information from Nopras FM has affected household standard of living. There is a strong statistical relationship between employment and Nopras FM's impact on household standard of living. Nopras FM's impact on household standard of living, scored highest amongst respondents who were in the "Self Employed (Agriculture) category, but scored lowest in the "Public/Civil/ Corporate" employee category. The test had 12 degrees of freedom and a probability ratio of ( $\mathrm{pr}<0.001$ ), this means there exists a significant statistical relationship at $5 \%$ confidence level. The Chi Square test is important because it supports field data and proves that the significant relationship between employment and impact of Nopras FM on household standard of living is not due to chance.

Table 1: Bivariate analysis of employment and respondents' views regarding Nopras FM's influence on household standard of living

\begin{tabular}{|l|l|l|l|l|l|l|}
\hline \multirow{2}{*}{ Employment } & \multicolumn{2}{l}{ Views of Respondents } & Total \\
\cline { 2 - 7 } & $\begin{array}{l}\text { Not in } \\
\text { any way }\end{array}$ & Somewhat & Moderate & $\begin{array}{l}\text { Very } \\
\text { Much }\end{array}$ & Vital & \\
\hline Unemployed/Inactive & 28 & 6 & 1 & 2 & 0 & 37 \\
\hline $\begin{array}{l}\text { Self-Employed } \\
\text { (Agriculture) }\end{array}$ & 5 & 11 & 55 & 44 & 27 & 142 \\
\hline $\begin{array}{l}\text { Self-Employed (Non- } \\
\text { Agriculture) }\end{array}$ & 5 & 54 & 49 & 8 & 7 & 123 \\
\hline Public/Civil/Corporate & 67 & 9 & 3 & 0 & 2 & 81 \\
\hline
\end{tabular}

Pearson chi Square (12) $=330.6463 \operatorname{Pr}<0.001$

\section{Participation in Programme Production}

Participation is very important in the activities and programming of Nopras FM. The station recognises that, for it to have an impact in the lives of the people it serves, there must always be an avenue for local people to contribute and make an input in programmes and activities. Therefore, audience participation is encouraged in every activity the station hosts:

We encourage participation, without audience participation, we won't know what effect we are having in the community and we wouldn't know if we are serving developmental needs or even broadcasting content 
which the people need. Through audience participation, we are able to calculate which programmes are more effective. (Field Interview, December 2017)

Survey results buttress the response of the station producers on participation. Respondents were asked if they contribute and participate in the programmes activities and running of Nopras FM. One hundred and eight respondents (28.1\%) responded in the negative, but two hundred and seventy-five (71.8\%), said they contribute to the programmes activities and running of Nopras FM.

\section{Means of Local Participation in Initiatives of Nopras FM}

Speaking on the means through which audience participate in programmes and development initiatives, the programme producers indicated that, several avenues exist for listener participation. They said the station has a dedicated SMS line through which opinions are collected and read during programmes. The station has a dedicated phone number which allows them to receive phone-in calls during certain programmes. This phone number allows them to call field journalists and other people for their input when the need arises. The most important form of participation is through outdoor and field programmes:

During outdoor programmes, we get to meet the most excluded people who may not have access to the phone or internet. Attendance to our public durbars are high, it is the most engaging method of participation in our opinion, because we get to meet the farmers and fishermen on the ground. We also interact with them and collect data which help us to create news stories and radio documentaries. (Field Interview, December 2017)

It was explained that some of these outdoor programmes are broadcast live on the station. At other times they are recorded and replayed at Radio Listenership Club (RLC) meetings. According to the station manager, RLC's are also very effective ways to participate because, the clubs can request particular programmes through their leaders and play them for their members. After this is done, members make contributions and ask questions from their leaders and station/programme representatives.

This interaction allows many new inputs to be made into subsequent editions of the programme, sometimes these interactions create new topics for the programme to address. The station is present on almost every popular social media platform, including Facebook and WhatsApp. This is because, they are trying to capture the attention of youth. Internet and social media present a cheaper way to communicate 
and obtain feedback compared to the other ways of communication. Ullah (2013) observes that youth that youths generally taking part in socio-political and civic activities take advantage of social networking sites such as Facebook to share ideas on different issues. It was found that the station has ways of making people participate through financial contributions. The radio station produces its own sachet water and also sells paraphernalia like shirts and caps at moderate prices. The profit from these ventures go to support the station financially in the payment of stipends for volunteers and running cost.

According to the representatives of the farmer groups, they and their organisations participate in radio programmes. They participate in production of radio programmes and also participate by giving feedback. They also avail themselves to the radio station anytime they are called upon for a capacity building workshop or in studio discussion. Usually, the radio stations identify the farming group which is needed for a particular topic.

When farmers present themselves for studio discussions, there are usually agriculture extension officers from the district assembly who also come to make input. Sometimes experts from other institutions within the district assembly are present to share ideas and make inputs on specific subjects. As a part of Nopras FM's broadcasting policy, every programme has time allocated for reading of audience text messages, social media posts and phone calls. This allows listeners to pose questions and gives them a chance to contribute to the overall development of their communities. This kind of participation can be likened to the kind of participation that Mikkelson (1995) calls, "interactive participation." In interactive participation, involvement is holistic and does not only take the form of information giving. There is a constant movement and exchange of ideas and opinions between the parties in the development process (Mikkelson 1995).

Results from the survey shows the preferred channel of contribution for respondents who said they contribute to the activities and programmes of community radio. Fifty-six respondents who claim to contribute to Nopras FM do so through phone calls, whilst thirty-three people identified Short Messaging Service (SMS) as their preferred means of contribution. A total of twenty-six respondents said they preferred to contribute by purchasing station products and paraphernalia. One hundred and twenty-six people said that their preferred means of contribution is through outdoor programmes and forums. Social media was selected by a total of twenty-two respondents as their preferred means of contribution and twenty people chose RLC meetings as their preferred means of contribution. 


\section{Problems Undermining Participation}

Over the last three and half years, Nopras FM has focused on agriculture and social development, and in particular issues related to the welfare of farmers in the Fanteakwa District and surrounding districts. To this end the station has worked with many development partners and NGO's within the community, district and national levels to contribute to the development of agriculture and help improve the lives of our farmers, but there are certain problems which undermine the participation of local people in development initiatives championed by Nopras FM. Notably, many community members are unaware of their roles as development agents in their communities. Many community members are unaware of the role they can play in the development of the community; as result many do not see the need to participate in Radio Listenership Clubs. (Field Interview, December 2017)

The leaders of the Farmer Based Organisations (FBOs) revealed that they were not consulted before the radio station was established. All they know is that the owner of the radio station is the cousin of a former Member of Parliament of the area. They said they were only informed about the broadcast style and focus of the radio station after it had been launched. This revelation runs contrary to the assertion by Inagaki (2007) that the community must be actively involved in all the processes from the planning to the establishment of the radio until the day it goes on air. The communities were not actively involved in the establishment process. The leader of the Vegetable Planters Group, noted that this undermines the participation of local people:

One day, they called us to meet at Begoro and that was when they told us that a new radio station was going to be set up, with agriculture as a focus... I don't really remember how I felt, because I did not know what they going to do for us. (Field Interview, December 2017)

The reason some members of the communities don't care about the development initiatives of the radio station is because they were not consulted before its establishment. The owners assumed because it was a community radio focused on agriculture, everybody will accept it intuitively. Going back to the types of participation, this kind of participation can be likened to what Mikkelson (1995) calls passive participation. This is the type of participation where beneficiaries are not consulted but are only told what will happen, or what has happened, without them having any opportunity to change or influence it (Mikkelson, 1995).

Respondents who said they do not contribute to the programmes and initiatives of Nopras FM were asked why they do not; $14.95 \%$ said they were simply not interested in contributing. Similarly, 33.64\% said they do not participate because they cannot 
influence decisions in anyway. About $34.58 \%$ of respondents said their reason for not contributing is because forums and programmes are held during working hours. Respondents who said they do not contribute because they lost interest when they weren't allowed to speak or their suggestions were not read on air were about $16 \%$.

\section{Maximising Participation in Development Initiatives}

Speaking on how the radio station has tried to maximise the participation of local people in development initiatives and dialogue, the radio producers explained that with the help of Farm Radio International (FRI) and state institutions like the Information Services Department (ISD) and the Skills Development Fund (SDF), more Radio Listenership Clubs (RLC) are being formed. These groups aim at giving local people a higher opportunity to participate in local development initiatives. This is done through the provision of community information systems and "Radio Apata" (Radio Huts). Even though these Radio Listenership Groups are available within the entire district, their primary focus is to help reach and involve people in the northern part of the district where communication infrastructure and internet networks are abysmal. Through the activities and programmes of FRI, radio receivers are shared to people and this helps in efforts to reach and involve as many people as possible. This means more people are exposed to the content of Nopras FM. Therefore, more people become involved in participating in development initiatives and dialogue which are championed by Nopras FM. According to Carpentier (2011), exposure to media content is the first step towards attracting the participation of local people.

As regards how community radio can improve their programmes and activities to benefit them in order to make them participate more in development initiatives, sixty respondents indicated that community radio must provide more knowledgeable presenters and resource persons. One hundred and ten respondents were of the view that, community radio must provide more practical training on issues which are discussed to enable them participate more. Forty respondents indicated that programmes and forums must be held at more convenient times. Twenty-three people asserted that for participation to improve, more time must be allocated for listener contributions during programmes and forums. One hundred and forty-nine respondents were of the view that community radio must organise more outdoor community programmes to enable them participate more.

\section{Contribution to Local Development}

The community radio station is serving the communities well, from the perspective of the District Director of Agriculture, who represented the district assembly in the 
study. Speaking on the future prospects of the radio station, the District Director of Agriculture acknowledged the work being done by the community radio. But also admitted that more needs to be done to properly integrate it into the lives of the people. He said in the future he will like to see equal attention being paid to all people in the district and also all kinds of livelihoods.

I am not saying their focus is bad, but I will love to see the station introduce more programmes to cover various aspects of the citizens' lives. I love the fact that they concentrate mostly on agriculture and its related activities but certain things like security and business development cannot be ignored because they all affect the livelihoods and development of the people. (Field Interview, December 2017)

The programme producers indicated that the radio station plays an important role in the Annual Agriculture Fair and Second Cycle School Agriculture Clubs. They explained that the Annual Agriculture Fair is a platform aims at bringing all stakeholders within the Aagriculture value chain together. The aim of bringing the stakeholders together is to create business, networking and friendship to improve the level of agricultural entrepreneurship within their catchment area. The Annual Agriculture Fair has been hosted every year since the station started broadcasting. The aim of the School Agricultural Club is to expose secondary school students to the ways in which agriculture is a sustainable employment choice. The radio station runs various programmes through talks, seminars and field demonstrations for the students. The radio station also hosts the annual Farmers' Day Soccer Competition. According to Diedong and Naaikuur (2015) the relevance of communication in community is that communication ought to facilitate the sharing and diffusion of values such as unity, peace and respect to foster a sense of togetherness of communities, which is key to initiating programmes and activities for community development.

\section{CONCLUSION AND RECOMMENDATIONS}

This study set out to examine how community radio as a tool for development by empowering communities. The conceptual framework of the study has shed light on how development initiatives require a process of interaction and sharing of information, skills and knowledge. The model does not treat community members as passive receivers of development initiatives but rather shows the power of community radio as a binding force, which puts local people in the driving seat of their development by facilitating dialogue among local people and between the development agents. 
This study supports the assertion of Carpentier (2011) and Inagaki (2007) that earlier models of development like modernisation do not give attention to local participation. Strategies of applying the modernisation paradigm are still being used today in development initiatives implemented by NGO's. The study concludes that such strategies alone cannot achieve much without the integration of participatory approaches, which are more people-centred and can be sustainable. The study proved that through local participation, community radio can facilitate a variety of development initiatives. Community radio has the potential to encourage local development through enhancing capabilities in a variety of ways; for example, Radio Listenership Clubs are used as training grounds to educate farmers on pesticide use and fertilizer application. This approach of community radio in local development affirms the argument that development should lead to the expansion of ordinary people's capabilities (Sen, 1992).

As regards the ideal definition of community radio as 'owned, managed and operated by members of the community' (Manyozo, 2009; Quebral, 2012 and Servaes, 1999), the study noted a contradiction to the general idea of community radio as communally owned ventures. Community radio stations which are individual ventures of entrepreneurs within the community have the tendency to reduce the emphasis on people, thereby reducing the participation of local people in playing active roles in governance and determining the course of their local development.

The government in collaboration with the National Media Commission (NMC) and the National Communications Authority (NCA) need to formulate a community radio broadcasting policy which is embedded in law. The policy should have clauses which state the nature of ownership of community radio stations and the role that private entrepreneurs and Non-Governmental Organisations can play in starting or operating community radio stations.

It is recommended that before registering community radio stations, the NCA needs to ensure that ownership of these radio stations are representative of every sub-group within the operating community. This would guarantee a measure of inclusiveness in management and development of content for the radio station. Bordenave (1998) argues that communal ownership of community radio stations serves as a check on entrepreneurs who establish community radio stations as businesses ventures with the aim of projecting the development agenda of donor agencies and NGOs.

Since the mandate of community radio includes giving people a voice and ensuring social inclusion, it is advisable for the NMC and the NCA to direct community 
radio stations to dedicate a section of their broadcast time to issues of national importance, such as gender empowerment and child protection and sanitation issues in order to keep local people at par with the broader national development concerns.

The managers and operators of community radio stations need to explore more income generation avenues. This would enable community radio stations to desist from depending on NGOs for funding. Exploring other income generation avenues will make community radio stations more self-sustaining.

Radio producers need to ensure that sure an equal opportunity is given to every RLC irrespective of location or professional influence. Since there are different types of clubs such as professional-based and location-based clubs, they can all be empowered to participate in the production of variety of programmes on different topics and issues that affect the community.

\section{References}

Ansah, P.A.V. (1979). Problems of localizing radio in Ghana. Gazette. 25(1), pp. 1-16.

Bamberger, M. (1988). The Role of community participation in development planning and project management. Washington: World Bank.

Barasa, F. and Jelagat, T. (2013). Community participation in project planning, management and implementation: Building the foundation for sustainable development. International Journal of Current Research, 5(02), pp. 398-40.

Bessette, G. (2004). Involving the community: a guide to participatory development communication. Ottawa, Canada: Southbound.

Bekye, P. (1998). Peasant development: The case of northern Ghana. Leuven: Acco.

Bordenave, J.D. (1994). Participative communication as part of building the participative society. In S. White with K. S. Nair and J. Ascroft (Eds.), Participatory communication: working for change and development (pp.35-48). New Delhi: Sage Publications.

Bordenave, J.D. (1994). Participative communication as a part of building the participative society. In S.A. White (ed.). Participatory communication: Working for change and development. Beverly Hills: Sage.

Boafo, K and George, N. (1991). Communication processes; alternative channels and strategies for development support. Ottawa: IDRC.

Carpentier, N. (2011). Media and participation: A site of ideological-democratic struggle. Bristol: Intellect. 
Carpentier, N. (2011). The concept of participation: If they have access and interact, do they really participate? Communication Management Quarterly, No. 21, pp. 13-36.

Diedong, L.A. and Naaikuur, L. (2012). Ghana's experience in participatory Community broadcasting. Global Media Journal, African Edition, 6(2), pp.123-147. . (2015). Who is the 'community' in community radio? A case study of Radio Progress in the Upper West Region, Ghana. Ghana Studies, 18, pp. 6889.

Dorvlo, L.K. (2006). Essays on community development. Ho: Maxvin Publicity Enterprise Ltd.

Farm Radio International. (2011). Participatory radio campaigns and food security:

How radio can help farmers make informed decisions. Available at: http://www. farmradio.org/pubs/farmradioprcreport2011.

Fraiser, C. and Estrada, S. R. (2001). Community radio handbook. Paris: UNESCO.

Inagaki, N. (2007). Communicating the impact of communications for development: recent trends in empirical research. Washington DC: World Bank.

Karikari, K. (1999). Development of community media in English-speaking West Africa. Background paper for UNESCO Regional Seminar on Promoting Community Media in Africa, Kampala, June 7-9, Uganda.

Kieffer, C. (1984). Citizen empowerment: A development perspective, Prev Human Serv. 6, pp. 18-33.

Media Diversity Journal. Gender Links: Southern Africa: Available at: http://www. genderlinks.org.za.

Lennie, J. and Tacchi, J. (2013). Evaluating communication for development: A framework for social change. Oxford: Routledge.

Lofland, J. and Lofland L.H. (1995). Analyzing social settings: A guide to qualitative observation (3rd ed.). Belmony: Wadsworth.

Lingela, M. B. (2008). Community broadcasting in SADC: An overview. Gender and

Manyozo Y. (2006), Manifesto for development communication: Nora C. Quebraland the Los Banos School of Development communication. Asian Journal of Communication, Vol 16 (1), pp. 79-99.

Mikkelsen, B. (1995). Methods of development work and research. Thousand Oaks, CA: Sage. 
Ugboajah, F. O. (1985). Oramedia. In: F. O. Ugboajah (ed.) Africa Mass communication, culture and society in West Africa., pp. 165-176. New York: K. G. Saur.

Ullah, M. (2013). ICTs changing youths' political attitudes and behaviour in Bangladesh. The International Communication Gazette, 73(3), pp. 271-283.

Quebral, N. (2012). The underside of communication in development. Nodicom Review, 33(Special Issue), pp. 59-64.

Reiser, R.A. and R.M. Gagne. (1982). Characteristics of media selection models. Review of Educational Research, 52(4), pp.499-512.

Rissel, C. (1994). Empowerment the holy grail of health promotion? Health promot int., 9, pp. 39-47.

Samah, A. and Aref, F. (2009). People's participation in community development: A case study in a planned village settlement in Malaysia. World Rural Observations, 1(2), pp. 45-54.

Sen, A. (1981). Poverty and famines: An essay on entitlement and deprivation. Oxford: Claredon Press.

Servaes, J. (1999). Communication for development: One world, multiple cultures. Creskill, NJ: Hampton Press.

Teer-Tomaselli R. and De Villiers, C. (1998). Radio: theatre of the mind. The South African handbook on mass communication. Pretoria: J. L. Van Schaik.

Varshney, A. (2002). Ethnicity and civil society. World Politics, 53(6), pp. 362-398.

Wallerstein, N. (1992). Powerlessness, empowerment and health: Implications for Health Promotion Programmes. Am J health promot, 6, pp.199-209. 